\title{
Effects of Different Disinfection Methods on Microleakage of Giomer Restorations
}

\author{
Abidin Talha Mutluay ${ }^{1}$ Merve Mutluay ${ }^{2}$ \\ ${ }^{1}$ Department of Restorative Dentistry, Faculty of Dentistry, Kirikkale \\ University, Kirikkale, Turkey \\ 2Department of Pediatric Dentistry, Faculty of Dentistry, Kirikkale \\ University, Kirikkale, Turkey
}

\begin{abstract}
Address for correspondence Abidin Talha Mutluay, Department of Restorative Dentistry, Faculty of Dentistry, Kirikkale University, Turkey (e-mail: abidintalhamutluay@hotmail.com).
\end{abstract}

Eur J Dent 2019;13:569-573

\begin{abstract}
Keywords

- cavity disinfection

- chlorhexidine

- Giomer

- laser

- microleakage
\end{abstract}

Objectives The purpose of this in vitro study was to investigate the effects of different disinfection methods on microleakage of Class $V$ Giomer restorations.

Materials and Methods Class $V$ cavity preparation was performed on 40 sound permanent central incisors. Class V cavities $(3 \times 2 \times 2 \mathrm{~mm}$ ) were prepared on the buccal surfaces of the selected teeth. The teeth were randomly divided into four groups, each to be disinfected with a different method: Group 1-Disinfection with $2 \%$ chlorhexidine, Group 2-Disinfection with 6\% sodium hypochlorite, Group 3-Disinfection with erbium, chromium: yttrium-scandium-gallium-garnet laser, Group 4-Control (distilled water). BeautiBond adhesive and Beautifil II Giomer restoration materials were applied to all surfaces of the cavities after the disinfection of all groups. The teeth were thermocycled 5,000 times $\left(5-55^{\circ} \mathrm{C}\right)$, and then were immersed in $0.5 \%$ methylene blue for 24 hours. After rinsing, the teeth were longitudinally sectioned and dye penetration was assessed under a stereomicroscope (40x) to evaluate microleakage.

Statistical Analysis The results were statistically evaluated by using the KruskalWallis and Mann-Whitney $U$ tests.

Results Statistically, no significant difference was found between all four groups $(p>0.05)$. There was no statistically significant difference in microleakage scores of study groups $(p>0.05)$. Also, the microleakage scores of the gingival margins were significantly higher than the incisal margins $(p<0.0001)$.

Conclusions Application of the different cavity disinfectants has no effect on the microleakage of Class $\vee$ Giomer restorations.

\section{Introduction}

Microbial factors, oral hygiene, and dietary habits may lead to caries formation in the cervical area of the teeth. ${ }^{1}$ Even if the initial lesions are asymptomatic, cervical caries may cause pain, tenderness and aesthetic defects in later stages. Resin materials are commonly used in the treatment of cervical caries lesions. ${ }^{2}$ Giomer is a resin-based restorative material, developed by adding glass ionomer-filler particles into composite resins, and indicated for use in Class V cavities. This hybrid material represents promising aesthetic and physical-mechanical properties similar to composite resins. Also, the fluoride charging and releasing ability offered by giomers has been claimed to be close to glass ionomer cements. ${ }^{3}$ However, the long-term fluoride release of Giomer is questionable, ${ }^{3}$ it has been reported to have demineralization inhibition properties such as glass ionomers in vitro. ${ }^{4}$

Necrotic and infected dentin tissues are intended to be completely removed from the cavity to maintain pulp vitality during the cavity preparation. ${ }^{5}$ Although most of the bacteria are found in the infected dentin layer, bacteria 
can also be found in small amounts in the hard and affected dentin at bottom of excavated cavity. ${ }^{1,5}$ Complete removal of infected dentin layers is essential to create a mechanically and biologically successful restoration. However, in the final stage of caries removal it is considerably difficult to make a visual diagnosis and distinguish the infected or affected dentin. ${ }^{6}$ Therefore, it is recommended to use an antibacterial cavity disinfectant following the cavity preparation to eliminate the risk of any pulpal inflammation caused by the microorganisms that may remain in the affected dentin. ${ }^{7}$ Various antibacterial agents and techniques such as chlorhexidine gluconate, potassium iodine, hydrogen peroxide, sodium hypochlorite $(\mathrm{NaOCl})$, laser, etc. are recommended for this purpose. Chlorhexidine gluconate-based solutions are the most commonly used materials as cavity disinfectants. Chlorhexidine's action mechanism is based on its chemical properties with strong cationic character. The negative charge on the surface of oral tissues interacts with the positively charged chlorhexidine molecule and creates a long-lasting antimicrobial effect. ${ }^{8,9} \mathrm{NaOCl}$, on the other hand, is a broad-spectrum antibacterial agent, which is effective against both Gram-positive and Gram-negative bacteria. It has organic tissue-dissolving ability and high efficacy against microorganisms organized in biofilms. $\mathrm{NaOCl}$ can be used to eliminate residual bacteria remaining in dentine tubules and cavity bottom after cavity preparation. ${ }^{10}$ However, there is a possibility that $\mathrm{NaOCl}$ as a cavity disinfectant may have adverse effects on hybrid layer formation or bond strength of composite resins. ${ }^{11}$

Laser irradiation has been recommended for cavity disinfection. Hard tissue lasers exhibit antibacterial effect, especially by evaporating the cellular liquid that expands by laser shot, causing the cell wall to break down. ${ }^{1}$ Laser irradiation provides reduction or total closure of dentinal tubules and intratubular fluid flow, which resulted in prevention on microleakage. ${ }^{12}$

Resin restorations show polymerization shrinkage that causes gap formation between the tooth tissues and the restoration. Bacterial products, oral fluids, and various ions can penetrate through the interface gap, which is defined as microleakage, and lead to postoperative sensitivity or discoloration of teeth, secondary caries, or pulpal pathologies. ${ }^{13}$ Besides, thermal expansion, inadequate adhesion of the restorative materials to the tooth tissues, or dissolution of restorative materials by oral fluids may cause microleakage. ${ }^{14}$

There are both benefits and drawbacks of using cavity disinfectant according to actual literature. Some researchers have claimed that cavity disinfectant application may cause microleakage between the tooth tissue and restoration. ${ }^{2,9}$ However, others have reported that the disinfections have no effect on the microleakage of restoration. ${ }^{6.8}$

The aim of this study was to investigate the effects of different disinfection methods on the microleakage of Giomer restorations. The null hypothesis was that cavity disinfectants did not affect the sealing capability of restorations.

\section{Materials and Methods}

In this study, 40 sound permanent bovine central incisors were used. The teeth were cleaned of debris and residual substances with a rubber-cup and fluoride-free polishing paste. The teeth were placed in distilled water containing $0.1 \%$ thymol for disinfection and kept there for 24 hours. $3 \times 2 \times 2 \mathrm{~mm}$ Class $\mathrm{V}$ cavities were prepared in the middle third of the buccal surfaces of the teeth. This process was done by using a high-speed head and diamond fissure burs (Diatech Dental AG, Sweden Dental Instrument, CH-9435 Heerbrugg, Switzerland) with water coolant. The depth of the cavities was standardized by means of a periodontal probe with millimeter markings. Teeth samples were then randomly divided into four groups $(n=10)$.

The disinfection procedures were indicated in - Table $\mathbf{1}$. After all the four groups were disinfected, BeautiBond (Shofu Inc., Kyoto, Japan) was applied to all surfaces of the cavities with the help of an applicator in accordance with the manufacturer's instructions. The bonding agent was polymerized for 20 seconds by using a LED light source with light intensity of $400 \mathrm{~mW} / \mathrm{cm}^{2}$ (Guilin Woodpecker Medical Instrument Co., Ltd, China).

Following the conditioning procedures, a single layer of Beautifil II (Shofu Inc., Kyoto, Japan) was applied on the cavities. All the samples were polymerized for 20 seconds at a light intensity of $400 \mathrm{~mW} / \mathrm{cm}^{2}$. All the restorative procedures were performed by one operator.

The finishing and polishing were performed by using diamond-finishing burs with a yellow ring and an OneGloss PC (Shofu Inc., Kyoto, Japan). The teeth were immersed in distilled water for 24 hours at $37^{\circ} \mathrm{C}$. Then all the teeth were thermocycled 5,000 times $\left(5-55^{\circ} \mathrm{C}\right)$, with a waiting period of 30 seconds and a transfer period of 10 seconds.

The tooth apices, which were then kept at $37^{\circ} \mathrm{C}$ for 24 hours, were tightly sealed with wax. The teeth were covered with two layers of nail polish to leave 1-mm thick sound enamel around the restorations. The teeth were immersed in $0.5 \%$ methylene blue at $37^{\circ} \mathrm{C}$ for 24 hours, after which they were taken out of the dye solution and rinsed thoroughly under running water until they were clear of dye residuals. The microleakage levels of the cross-sectioned teeth were examined under a stereomicroscope (Zeiss, Germany) at 40x magnification.

Table 1 Disinfection methods used in the study

\begin{tabular}{|l|l|l|}
\hline Group & Treatment procedure & Manufacturer \\
\hline Group 1 & $\begin{array}{l}\text { CHX 2\% chlorhexidine } \\
\text { gluconate treatment } \\
\text { with rinsing and drying }\end{array}$ & $\begin{array}{l}\text { Cavity Cleanser, } \\
\text { Bisco, Schaumburg, } \\
\text { Illinois, United States }\end{array}$ \\
\hline Group 2 & $\begin{array}{l}6 \% \mathrm{NaOCl} \text { treatment } \\
\text { with rinsing and drying }\end{array}$ & $\begin{array}{l}\text { RC CLEANER, } \\
\text { ilchungdental, Seoul, } \\
\text { Korea }\end{array}$ \\
\hline Group 3 & $\begin{array}{l}\text { Er,Cr:YSGG laser, 20 Hz; } \\
0.75 W ; 15 \% \text { water, 15\% } \\
\text { air and drying }\end{array}$ & $\begin{array}{l}\text { iPlus; Waterlase, } \\
\text { Biolase, California, } \\
\text { United States }\end{array}$ \\
\hline Group 4 & $\begin{array}{l}\text { Distilled water with } \\
\text { rinsing and drying }\end{array}$ & - \\
\hline
\end{tabular}

Abbreviations: Er,Cr:YSGG, erbium, chromium: yttrium-scandium-gallium-garnet; $\mathrm{NaOCl}$, sodium hypochlorite. 


\section{Statistical Analysis}

The results of microleakage evaluation were submitted to statistical analysis using "SPSS 15.0" computer software (SPSS 15.0; SPSS Inc, United States). Kruskal-Wallis and Mann-Whitney $U$ tests were performed. Significance was predetermined at $p<0.05$.

\section{Results}

The examples of cross-sectioned teeth with microleakage were presented in - Fig. $\mathbf{1}$. The microleakage scores were determined by using the criteria given in - Table 2 . Distribution of microleakage scores according to groups were shown in - Table 3.

The results of the Kruskal-Wallis test indicated that there was no significant differences among the microleakage scores of the different groups $(p>0.05)$. Mann-Whitney $U$ test showed no significant difference in microleakage scores between paired groups both for incisal and gingival margins $(p>0.05)$. On the other hand, the microleakage scores of gingival margins were significantly higher than that in the incisal margins $(p<0.0001)$.

\section{Discussion}

Cervical caries is a common type of caries caused by inadequate oral hygiene, cariogenic diet and bacteria. ${ }^{2}$ After caries removal, the existence of residual bacteria within a restoration may lead to microleakage and secondary caries. $^{13}$ Therefore, disinfection of the dentine surface is recommended before any restorative material is placed into the cavity. ${ }^{7}$ Several agents and techniques, such as chlorhexidine gluconate, potassium iodine, hydrogen peroxide, $\mathrm{NaOCl}$, and laser, are frequently used for this purpose. ${ }^{89}$ In this in vitro study, we compared four different disinfection methods on the microleakage of Giomer resin material in Class $\mathrm{V}$ restorations of permanent bovine central incisors.

It is recommended to store the extracted teeth in distilled water, glutaraldehyde, or thymol solutions for in vitro tests. ${ }^{15,16}$ In the present study, the extracted teeth were first disinfected in distilled water containing $1 \%$ thymol at room temperature for 24 hours after the tooth extraction, and then kept in distilled water at $37^{\circ} \mathrm{C}$ for 24 hours following polishing procedure.

Eating, drinking, and breathing cause temperature changes within the mouth. Intraoral temperature changes

Table 2 Scoring chart used to evaluate microleakage levels

\begin{tabular}{|c|l|}
\hline 0 & No microleakage \\
\hline 1 & Penetration up to one-third of the cavity depth \\
\hline 2 & $\begin{array}{l}\text { Penetration between one-third up to two-thirds of the } \\
\text { cavity depth }\end{array}$ \\
\hline 3 & $\begin{array}{l}\text { Penetration into more than two-thirds of the cavity } \\
\text { depth up to the axial wall or toward the pulp }\end{array}$ \\
\hline
\end{tabular}

Table 3 Distribution of microleakage scores according to groups

\begin{tabular}{|l|l|l|l|l|l|}
\hline \multicolumn{2}{|c|}{} & \multicolumn{5}{|c|}{ Microleakage scores } \\
\cline { 3 - 6 } \multicolumn{2}{|c|}{} & $\mathbf{0}$ & $\mathbf{1}$ & $\mathbf{2}$ & $\mathbf{3}$ \\
\hline \multirow{3}{*}{ Group 1 } & Gingival & 0 & 0 & 0 & 10 \\
\cline { 2 - 6 } & Incisal & 1 & 7 & 1 & 1 \\
\hline \multirow{3}{*}{ Group 2 } & Gingival & 0 & 1 & 0 & 9 \\
\cline { 2 - 6 } & Incisal & 2 & 8 & 0 & 0 \\
\hline Group 3 & Gingival & 0 & 0 & 0 & 10 \\
\cline { 2 - 6 } & Incisal & 2 & 5 & 0 & 3 \\
\hline \multirow{2}{*}{ Group 4 } & Gingival & 0 & 0 & 0 & 10 \\
\cline { 2 - 6 } & Incisal & 1 & 5 & 1 & 3 \\
\hline
\end{tabular}
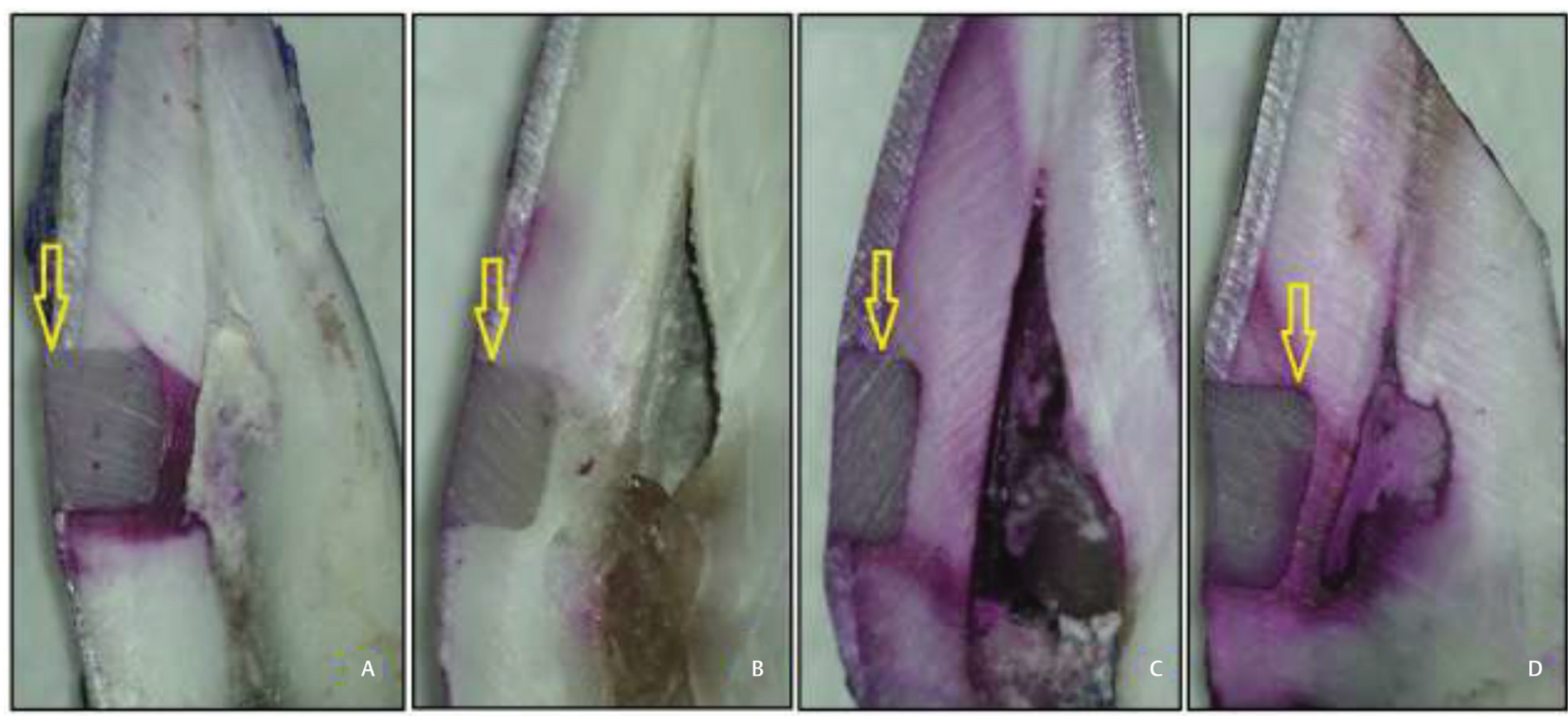

Fig. 1 The arrowheads show microleakage levels between the restoration and tooth surface of two-dimensional specimens. (A) Score 0 , no leakage; (B) Score 1, leakage depth up to one-third of the internal surface; (C) Score 2, leakage depth up to two-thirds of the internal surface. (D) Score 3, leakage into more than two-thirds of the cavity depth up to the axial wall or toward the pulp. 
cause thermal stresses in the adhesive bonding between the tooth and the restoration interface. Effects of longterm exposure to temperature and humidity changes can be simulated by means of thermal cycling. Thermal cycling is frequently used in experiments where the performance of adhesive materials is examined. ${ }^{17}$ Also, it is preferred in microleakage studies to age restorations clinically. It is believed that this method provides rather reliable results in microleakage experiments. ${ }^{18}$ In this study, all the teeth were thermocycled 5,000 times $\left(5-55^{\circ} \mathrm{C}\right)$ before the microleakage test.

In vitro microleakage tests are attempt to assess sealing ability of restorative materials. ${ }^{19}$ Chemical markers, scanning electron microscope analysis, neutron activation analysis, autoradiography, and dye leakage methods have been recommended to evaluate microleakage. Using organic dyes in microleakage studies is one of the oldest methods and still preferred to other techniques. Silver nitrate (50\%), methylene blue $(0.2-2 \%)$, crystal violet $(0.05 \%)$, erythrosine (2\%), rhodamine B $(0.2 \%)$, and basic fuchsine $(0.5-2 \%)$ are generally using dye solutions. ${ }^{2,20,21}$ In the present study, $0.5 \%$ methylene blue solution was used to assess the microleakage of restorative materials. This technique is preferred for microleakage studies due to simple and inexpensive application.

Similar microleakage studies regarding to cavity disinfectants indicated several results. Türkün et $\mathrm{al}^{8}$ examined effect of chlorhexidine, benzalkonium chloride, and iodine-based cavity disinfectants on the sealing ability of different dentin adhesives. They have reported that the use of chlorhexidine- and benzalkonium chloride-based solutions as cavity disinfectants had no effect on the microleakage while iodine-based solutions increased it. Another study investigating the effect of using ethanol, chlorhexidine, and $\mathrm{NaOCl}$ as a cavity disinfectant on microleakage showed that these solutions did not increase the microleakage. ${ }^{6}$ Tulunoglu et al, ${ }^{9}$ on the other hand, reported that the use of chlorhexidine-based cavity disinfectant had a negative effect on dentin adhesive systems. The present study showed that all samples exhibited microleakage when assessed under the microscope magnification. We observed that cavities restored with Giomer have similar microleakage scores with or without different cavity disinfection methods. These results were in accordance with previous studies. ${ }^{6,8}$

The lasers are capable of removing the smear layer which contains residual bacteria and disinfect the dentinal tubules. ${ }^{1}$ The antibacterial effect of lasers is related to many factors including the laser's energy output, water content and volume of the cell, cell wall stability, absorption properties, and movements of bacteria in the dentine tubules. ${ }^{22}$ Kouchi et a ${ }^{23}$ showed that streptococcus mutans may exist in dentine at depths of 1,050 to $1,150 \mu \mathrm{m}$. It was shown that the antimicrobial activity of chlorhexidine gluconate in a $500-\mu \mathrm{m}$ thick dentine goes down to $54 \%,{ }^{24}$ while a diode laser could kill $90.8 \%$ of the microorganisms at $5 \mathrm{~W}$ and $97.7 \%$ at $7 \mathrm{~W}$ for the same dentine thickness. ${ }^{22}$ In a study conducted by Türkün et al, ${ }^{1}$ erbium, chromium: yttrium-scandium-gallium-garnet ( $\mathrm{Er}, \mathrm{Cr}$ : YSGG) laser with power outputs $0.75 \mathrm{~W}$ and $1 \mathrm{~W}$ and a chlorhexidine-based cavity disinfectant were compared in terms of antibacterial activity, and it was reported there was no significant difference between the two methods and lasers could be used for cavity disinfection, but it was not an economical method. In a study on the effect of potassium-titanyl-phosphate (KTP) laser radiation, $2 \%$ chlorhexidine gluconate, and Clearfil Protect Bond on the microleakage of Class V composite restorations, KTP lasers were reported to reduce the microleakage to a statistically significant extent. In the present study, no statistically significant difference was observed when the microleakage scores related to the use of Er, Cr: YSGG laser with a power output of $0.75 \mathrm{~W}$ were compared with the scores of the other groups.

Studies examining the microleakage of Class $\mathrm{V}$ restorations reported that gingival edges of cavities showed higher microleakage than the incisal edges, ${ }^{25,26}$ which were attributed to the fact that the enamel layer in the cervical region is thinner, and therefore more permeable than the enamel layer at the incisal edge. ${ }^{25}$ In fact, in the present study, the microleakage scores of gingival margins showed were significantly higher than the incisal margins.

\section{Conclusion}

The results of present study indicate that the cavity disinfectant application has no effect on the microleakage of Class $\mathrm{V}$ Giomer restorations. These findings should be supported with long-term clinical trials.

\section{Funding \\ None.}

\section{Conflict of interest}

None declared.

\section{References}

1 Türkün M, Türkün LS, Celik EU, Ateş M. Bactericidal effect of Er,Cr:YSGG laser on Streptococcus mutans. Dent Mater J 2006;25(1):81-86

2 Manhart J, Chen HY, Mehl A, Weber K, Hickel R. Marginal quality and microleakage of adhesive class $\mathrm{V}$ restorations. J Dent 2001;29(2):123-130

3 Deliperi S, Bardwell DN, Wegley C, Congiu MD. In vitro evaluation of giomers microleakage after exposure to $33 \%$ hydrogen peroxide: self-etch vs total-etch adhesives. Oper Dent 2006;31(2):227-232

4 Gonzalez EdeH, Yap AU, Hsu SC. Demineralization inhibition of direct tooth-colored restorative materials. Oper Dent 2004;29(5):578-585

5 Fuks AB. Pulp therapy for the primary and young permanent dentitions. Dent Clin North Am 2000;44(3):571-596, vii

6 Salama F, Balto H, Al-Yahya F, Al-Mofareh S. The effect of cavity disinfectants on microleakage of composite restorations in primary teeth. Eur J Paediatr Dent 2015;16(4):295-300 
7 Gultz J, Do L, Boylan R, Kaim J, Scherer W. Antimicrobial activity of cavity disinfectants. Gen Dent 1999;47(2):187-190

8 Türkün M, Türkün LS, Kalender A. Effect of cavity disinfectants on the sealing ability of nonrinsing dentin-bonding resins. Quintessence Int 2004;35(6):469-476

9 Tulunoglu O, Ayhan H, Olmez A, Bodur H. The effect of cavity disinfectants on microleakage in dentin bonding systems. J Clin Pediatr Dent 1998;22(4):299-305

10 Mutluay AT, Mutluay M. Sodium hypochlorite in endodontics. J Dent Fac Atatürk Uni 2015;25:258-265

11 Pappas M, Burns DR, Moon PC, Coffey JP. Influence of a 3-step tooth disinfection procedure on dentin bond strength. J Prosthet Dent 2005;93(6):545-550

12 Obeidi A, Ghasemi A, Azima A, Ansari G. Effects of pulsed $\mathrm{Nd}$ :YAG laser on microleakage of composite restorations in class V cavities. Photomed Laser Surg 2005;23(1):56-59

13 Brännström M. Communication between the oral cavity and the dental pulp associated with restorative treatment. Oper Dent 1984;9(2):57-68

14 Feilzer AJ, De Gee AJ, Davidson CL. Curing contraction of composites and glass-ionomer cements. J Prosthet Dent 1988;59(3):297-300

15 Titley KC, Chernecky R, Rossouw PE, Kulkarni GV. The effect of various storage methods and media on shear-bond strengths of dental composite resin to bovine dentine. Arch Oral Biol 1998;43(4):305-311

16 Eronat N, Yilmaz E, Kara N, Topaloglu AA. Comparative evaluation of microleakage of nano-filled resin-modified glass ionomer: an in vitro study. Eur J Dent 2014;8(4):450-455
17 Gale MS, Darvell BW. Thermal cycling procedures for laboratory testing of dental restorations. J Dent 1999;27(2):89-99

18 Uno S, Finger WJ, Fritz UB. Effect of cavity design on microleakage of resin-modified glass ionomer restorations. Am J Dent 1997;10(1):32-35

19 Tay FR, Gwinnett AJ, Pang KM, Wei SH. Variability in microleakage observed in a total-etch wet-bonding technique under different handling conditions. J Dent Res 1995;74(5):1168-1178

20 Friedl KH, Schmalz G, Hiller KA, Märkl A. Marginal adaption of Class $\mathrm{V}$ restorations with and without "softstart-polymerization" Oper Dent 2000;25(1):26-32

21 Yazici AR, Celik C, Dayangac B, Ozgunaltay G. Effects of different light curing units/modes on the microleakage of flowable composite resins. Eur J Dent 2008;2(4):240-246

22 Lee BS, Lin YW, Chia JS, et al. Bactericidal effects of diode laser on Streptococcus mutans after irradiation through different thickness of dentin. Lasers Surg Med 2006;38(1):62-69

23 Kouchi Y, Ninomiya J, Yasuda H, Fukui K, Moriyama T, Okamoto H. Location of Streptococcus mutans in the dentinal tubules of open infected root canals. J Dent Res 1980;59(12):2038-2046

24 Schmalz G, Ergücü Z, Hiller KA. Effect of dentin on the antibacterial activity of dentin bonding agents. J Endod 2004;30(5):352-358

25 Kucukesmen HC, Kucukesmen C. Comparison of microleakage levels of class-V hybrid composite resin restorations. Balikesir Health Sci J 2012;1:110-116

26 Walshaw PR, McComb D. Clinical considerations for optimal dentinal bonding. Quintessence Int 1996;27(9):619-625 